\title{
Employment Issues among Ethnic Minorities: The Case of Vietnam
}

\author{
Pham Thi Phuong Thai ${ }^{1}$, Ta Thi Thao ${ }^{2}$, Vo Thi Hong Hanh3, Vu Ngoc Xuan ${ }^{4, *}$ \\ ${ }^{1}$ Thai Nguyen University of Science \\ Vietnam \\ ${ }^{2}$ Thai Nguyen University of Science \\ Vietnam \\ ${ }^{3}$ National Economics University, Hanoi \\ Vietnam \\ ${ }^{4}$ National Economics University, Hanoi \\ Vietnam \\ *Corresponding author's email: xuanvn [AT] neu.edu.vn
}

\begin{abstract}
Labor and employment issues, especially among ethnic minorities (EM), are always considered to be the most important task in our Party and State guidelines and guidelines. In order to achieve the goal of sustainable development, employment policies are evaluated as the basic solution. Currently, the gap between rich and poor as well as social differentiation between ethnic minorities and ethnic minorities (ethnic minorities) (16 ethnic groups) residing in rural and mountainous areas compared to the country is quite large; The main reason is due to the underemployment of ethnic minority groups, which provides stable income, the main field of employment in agriculture and forestry. The study focused on investigating the Chut ethnic group, Quang Binh province and the $O$ Du ethnic group, Nghe An province. By analyzing and synthesizing materials used in the research, on the basis of secondary and primary data sources, the author analyzes the situation and causes of the underemployment among ethnic minorities currently.
\end{abstract}

Keywords---- ethnic minorities (EM), ethnic minorities (DTTSRIN), employment (JO), labor (LA).

\section{INTRODUCTION}

According to the survey of 53 ethnic minorities in 2016, 53 ethnic minorities have about 13.4 million people (accounting for 14.6\% of the national population) with 3.04 million households. Including 6 ethnic groups with a population of over 1 million, 16 ethnic groups with a population of less than 10,000 people (collectively referred to as ethnic minority groups), of which 5 ethnic groups with a population of less than 1,000 people include: Si La, Pu Péo , Ro Mam, Brau and O Du. According to the Decision No. 582 / QD-TTg of the Prime Minister, our ethnic minority and ethnic minority regions are in the areas of 51 provinces and cities, 548 districts and 5,266 commune-level administrative units, mainly in the Northwest and Western regions. Central Highlands, Southwest and Central Coast [1]. Ethnic minorities live in communities mainly in mountainous areas, borders, remote areas, remote areas and areas facing extreme hardship with divided terrain, difficult transportation. The Northern Midlands and Mountains region has the highest number of ethnic minorities (about 6.7 million people), the Central Highlands region (about 2 million people), the North Central and Central Coast regions (1.9 million people).), the Southwest region (1.4 million people), the rest live scatteredly in provinces and cities across the country. Most of ethnic minorities live in mountainous areas, only Khmer, Cham, Chinese live in plains and urban areas. Ethnic minority groups all live in community, intertwined with the Kinh people. [1]

The livelihoods of ethnic minorities today are mainly in the fields of agriculture and forestry. The rate of ethnic minority groups having jobs in industry, construction and a service is limited, not yet exploiting the potential in the field of tourism and services of the region. The average income per capita of ethnic minorities currently is about 1.1 million / person / month, less than $1 / 2$ compared to the national average, while the ethnic minority group has an income equal to only bằng Compared to the common ethnic group, among the two ethnic groups surveyed are the Chut and $\mathrm{O} D u$ ethnic groups, the income is below 632,000 / person / month [1]. 


\section{THEORETICAL FRAMEWORK}

\section{* Theoretical framework}

Table 1: Theoretical framework

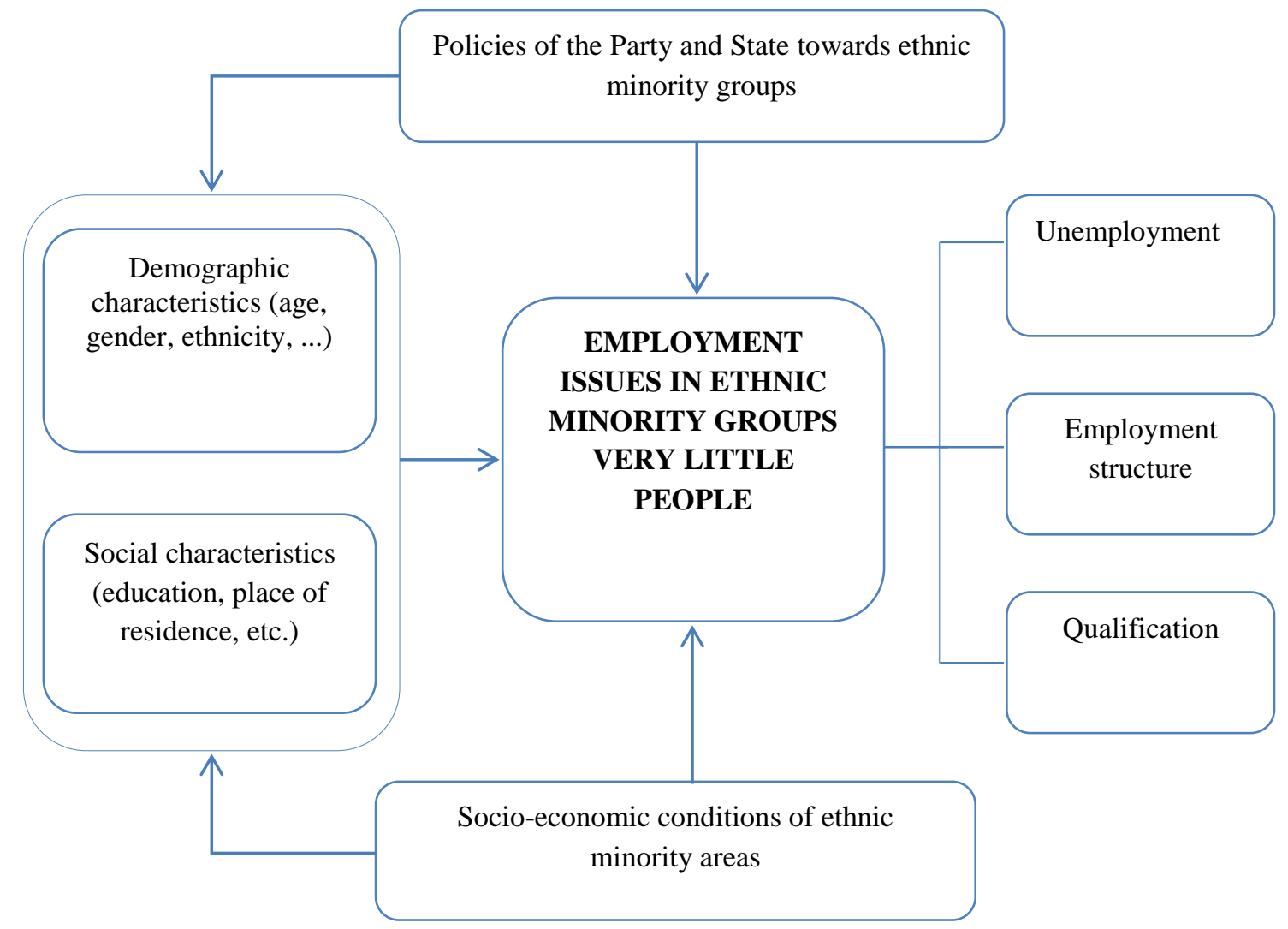

(Source: author's group)

The information in the article was collected from the author's field survey in 2 provinces with the number of people. The Chut and O Du ethnic groups are concentrated in Quang Binh and Nghe An. These are two provinces in the North Central region of Vietnam, with specific economic - cultural - social characteristics of the Central Coast region. For the Chut ethnic group, the author conducted surveys in 2 districts of Lam Hoa and Tuyen Hoa in Quang Binh province; For O Du ethnic group, the author surveyed in Tuong Duong district, Nghe An province.

\section{*Quang Binh Province}

Chut Ethnic in Quang Binh Province with 5 peoples: Books, You, RUC, A Rem, Ma Lieng. As of December 31, 2018, the Chut ethnic population in Quang Binh has 1,743 households with 6,935 people. The residence is predominantly in Minh Hoa, Tuyen Hoa and Bo Trach districts (with the smallest Chut population, 81 households with 349 people), in mountainous, highland and border communes; where the terrain is fragmented and rugged; extreme weather, flooding in the rainy season; drought, lack of water in dry season; high differential amplitude. [5]

- Tuyen Hoa district is a mountainous district in the Northwest of Quang Binh province, with a total natural area of 112,869.39 hectares, a population of over 80,030 people, including 209 households with 739 people. Chut, living together in 4 villages of 2 communes Thanh Hoa and Lam Hoa.

- Minh Hoa district, a highland mountainous district, located to the northwest of Quang Binh province. The West borders Lao People's Democratic Republic with $89 \mathrm{~km}$ of the border, the North borders Tuyen Hoa district, the South and the Southeast borders with Bo Trach district. The district has 15 communes and 1 town with a natural area of $1,410 \mathrm{~km}^{2}$. The population is over 49,000 people, including 1,453 households with 5,802 people of the Chut ethnic group, with community-based residence in 24 villages in 6 communes.

\section{* Tuong Duong District - Nghe An Province}

As a mountainous region, the border is located southwest of Nghe An province, is one of 62 poorest districts in the country, $180 \mathrm{~km}$ from Vinh city center. The natural area is 280,777.68 ha, accounting for $17 \%$ of the total area of the province. There are 6 ethnic groups residing in the district, namely Thai (71\%), Kho Mu (13.2), Kinh (9.1\%), Mong (4.8\%), Tho (1.1\%) and O Du. (0.59\%). It can be seen that the O Du ethnic group accounts for a very small percentage of the community of ethnic minorities residing in this district. Due to the small population, O Du people previously mixed with Thai and Kho Mu ethnic groups; they don't have separate versions. After 2006, following the policy of the 
Party and the State on resettlement of Ban Ve hydropower project, O Du people settled in Van Mon village, Nga My commune, Tuong Duong district, up to now, the number of O ethnic households Swing is 103 households with 445 people.

\section{CURRENT SITUATION OF EMPLOYMENT}

Results from the 2015 national survey on socio-economic situation of 53 ethnic minorities in Vietnam showed that the gap between ethnic minority groups and Kinh people is still large and persistent. in many socio-economic fields. The overall poverty rate for ethnic minorities in 2015 was $23.1 \%$, nearly 4 times higher than the general rate of other countries, in particular 14 ethnic minorities had a very high rate of poor households from $41 \%$ or more. Ethnic minority groups are disadvantaged compared to the majority of the population in terms of education and employment, ability to relocate places of residence, employment, access to financial services, productive resources such as land, access to markets. due to being attached to a pattern as well as other cultural barriers. Accordingly, the outstanding characteristic of ethnic minorities is that they participate in working from a very young age and most of the ethnic minority people in working age are working, this is reflected in the proportion of ethnic minorities aged 15 and over. employment in 2015 reached $87.55 \%$, significantly higher than the corresponding rate of the Kinh of $74.92 \%$.

Table 2. Employment status of ethnic minorities aged 15 and over by ethnic group as of August 1, 2015 [1]

\begin{tabular}{|c|c|c|c|}
\hline \multirow[t]{2}{*}{ Ethnicity } & \multirow{2}{*}{$\begin{array}{c}\text { Number of people aged } 15 \text { and older } \\
\text { who have a job (unit: person) } \\
\text { ( } \sum \text { Ethnic Minority) employed=8,079,186 people) }\end{array}$} & \multicolumn{2}{|c|}{ Employment structure by sex (unit :\%) } \\
\hline & & Male & Female \\
\hline Split & $3,368(0.04 \%)$ & 54.7 & 45.3 \\
\hline $\mathrm{O} \mathrm{Du}$ & $235(0.003 \%)$ & 55,4 & 44.6 \\
\hline
\end{tabular}

(Source: authors)

Survey results show that the proportion of the Chut and O Du ethnic groups who have a job is very low compared to other ethnic groups and low compared to the total population; The proportion of male workers with jobs is higher than that of females. Underemployment among working-age population is an urgent issue in ethnic minority communities in general and for $\mathrm{O}$ Du and Chut ethnic groups in particular. [3], [4].

Table 3. Employment status of ethnic minorities by age group, by ethnic group in the time

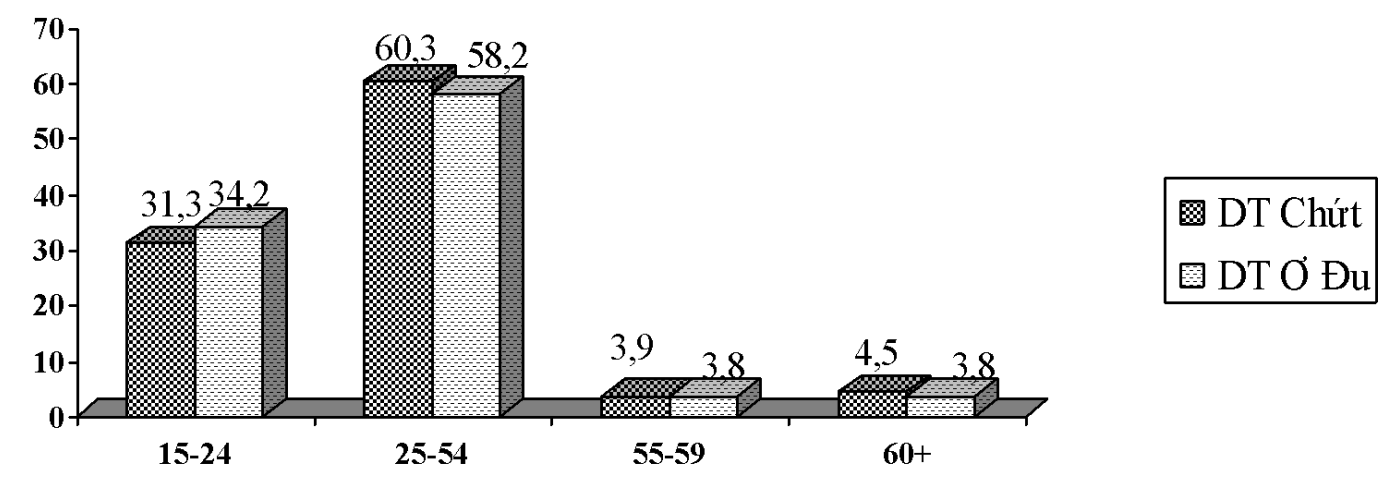

The employment structure of ethnic minority people is still quite backward, mostly associated with agriculture and forestry. Most of EM people work and they accept heavy work and low income. Therefore, their unemployment rate is very low compared to the general unemployment rate of the whole country. The higher the proportion of ethnic minorities is working in agriculture, the lower the unemployment rate is, even the unemployed. 
Table 4: Employment structure by economic sector and ethnic group by August 1, 2015

(Unit:\%) [1]

\begin{tabular}{|c|c|c|c|}
\hline Ethnicity & $\begin{array}{c}\text { The proportion of } \\
\text { employed population in } \\
\text { agriculture, forestry and } \\
\text { fishery the }\end{array}$ & $\begin{array}{c}\text { proportion of workers in } \\
\text { the construction industry } \\
\text { and the }\end{array}$ & $\begin{array}{c}\text { proportion of workers in } \\
\text { the service sector }\end{array}$ \\
\hline Chut & 94.9 & 1.0 & 4.1 \\
\hline Odu & 94.3 & 0.9 & 4.8 \\
\hline
\end{tabular}

(Source: complied by the authors)

"About Basically, the ethnic groups of the Chut ethnic group all get income from shifting cultivation, hunting, gathering as their main source of income. With the characteristics of self-sufficiency, self-sufficient, closed, very low rate of goods, outdated farming techniques, rudimentary production tools according to the custom of "burning, burning, reinforcing, slitting", so the productivity is low. Cultivation in the form of fire farming ... the people who practice milpa often suffer from food shortages and still have many backward remnants ... " (IDI, Vice Chairman of the commune, Minh Hoa district, Quang Binh)

" O Du people live on the fields Upland rice, rice is the main food source, cassava is a secondary food. Picking and hunting still plays an important role in $O$ Du's economic life. They raise cattle and buffaloes in insignificant amount to get the traction; raising pigs and chickens are often used for rituals, worshiping and improving meals, especially for the occasion of having guests to exchange.... " (IDI, Vice Chairman of the Commune, Tuong Duong District, Nghe An)

According to the report 53 ethnic groups, when dividing the employment structure by occupation can see the paid work, name, O Du and Chut participation rate is very low; More than $90 \%$ of the population in these two ethnic groups engages in simple labor jobs, which do not require technical expertise.

Table 5: Employment structure by occupation and ethnicity as of August 1, 2015 (Unit:\%) [1]

\begin{tabular}{|l|c|c|}
\hline \multicolumn{1}{|c|}{ Job group } & Chay & O Du \\
\hline Leaders & 0.2 & 0.0 \\
\hline Professionals High-tech subjects & 0.4 & 1.9 \\
\hline Medium-tech professionals & 0.4 & 0.9 \\
\hline Employees & 0.4 & 0.0 \\
\hline Personal services, protection and sales & 0.9 & 0.9 \\
\hline Labor with skills in agriculture, forestry and fishery & 7.6 & 0.0 \\
\hline Craftsmen and other relevant workers & 0.6 & 0.9 \\
\hline Collectors and operators of machinery and equipment & 0.2 & 0.9 \\
\hline Unskilled labor single & 89.3 & 94.5 \\
\hline
\end{tabular}

Field survey shows that the O Du ethnic group in Tuong Duong district (Nghe An) has 326 people of working age, only 62 people work away from home. Phuong); In the Chut ethnic group, in the two districts surveyed, the Chut people in the working age were 652 people, of which about 100 were working far from the locality. Thus, it can be seen that the integration of employment among working-age groups in both ethnic groups is very limited. Mainly the population resides and unskilled labor in the locality.

Table 6. Number of professionally trained workers (from Intermediate - University) employed by ethnic group (unit: person)

\begin{tabular}{|l|c|c|c|c|}
\hline \multirow{2}{*}{ Training major } & \multicolumn{2}{|c|}{ Chut } & \multicolumn{2}{c|}{ O Du } \\
\cline { 2 - 5 } & Number trained & $\begin{array}{c}\text { Number of } \\
\text { employed }\end{array}$ & $\begin{array}{c}\text { Number trained } \\
\text { Create a }\end{array}$ & $\begin{array}{c}\text { number with } \\
\text { jobs }\end{array}$ \\
\hline Public security and & - & - & 02 & 02 \\
\hline Medical sector & 01 & 01 & 11 & 04 \\
\hline Agriculture - forestry & 02 & 02 & 03 & - \\
\hline Education & 07 & 04 & 01 & - \\
\hline
\end{tabular}

(Field survey data, 2019)

Ethnic minority situation in general receive professional training but no job has been offered at the Workshop on building a contingent of ethnic minority officials organized by the Central Organization Board, the Central Commission 
for Civil Affairs and the Ministry of Home Affairs; According to the latest statistics in 12 provinces of the Northwest, Western Thanh Hoa and Western Nghe An, about 40,000 ethnic minority people have been trained at colleges and universities but have not had jobs. This is a consequence of the training of labor as well as the training of ethnic minority cadres, which are still inadequate, especially the training that is not linked to the staff planning, leading to where there is a shortage and where there is no need. redundant.

\section{SOME CAUSES}

First, the quality of EM labor is generally very low. About $75 \%$ of the population of ethnic minority and mountainous areas are at working age, while the process of globalization, the labor force is increasingly required to be skilled, flexible, dynamic and always interested. to meet the labor needs of the labor market. In the two ethnic groups surveyed, the percentage of adults who can read and write in Mandarin is $62.9 \%$ (Chut ethnic group) and $91.9 \%$ (O Du ethnic group - The reason for this rate is due to now O Du people can only use Thai, Khmer, and Vietnamese fluently in daily communication, the original O Du language has faded, and the number of people who are able to speak is no longer much); in which the rate of trained laborers in the Chut ethnic group is $2.8 \%$ and $\mathrm{O}$ Du is $3.8 \%$.

Secondly, the State has issued a number of policies to encourage enterprises in using local labor in ethnic minority areas, but it is difficult to attract labors in this area. In many places such as the Northwest and the Central Highlands, businesses do not or very little use of local ethnic minority laborers, but most of them bring workers from other places (mainly labors from the plains). raises many complex issues. In particular, for ethnic minorities, due to population limitations, they are afraid to work far from home, unfamiliar with industrial working environment and lack of confidence, they are afraid of the majority ethnic groups deceiving themselves, so , it is difficult for them to find a better job to increase their income. At the same time, the regions where most of the ethnic minorities live are mountainous, remote areas, with unfavorable traffic conditions, thus lacking attraction to investors.

Thirdly, due to the socio-economic weakness, the high rate of poor households (over $60 \%$ in both ethnic groups), the low self-esteem, and the expectation and dependence in the community. making it difficult for EM people to access employment. The basic problem lies in people's awareness. Because the State currently has quite a lot of preferential lending policies for poor and near-poor households with a variety of subjects and purposes from the Bank for Social Policies. However, ethnic minority groups are still facing many difficulties in accessing, especially solutions to use loans effectively. On the other hand, there is no preferential credit policy for households who can start businesses and start businesses to create jobs and income for local people.

\section{CONCLUSION}

Ethnic minority areas have been and are the "poor core of the country": the per capita income of ethnic minorities is only about $30 \%$ of the national average. Ethnic minority population accounts for $14.6 \%$ of the national population but the poverty rate accounts for $52.66 \%$ of the country's poor households. Facing that situation, the Party and the State have issued many employment policies for ethnic minority laborers, especially for ethnic minorities with many different forms of support and obtained positive results, the percentage The number of poor households has decreased, and their material and spiritual life has been improved. However, compared to the current actual requirements, there are still many shortcomings and shortcomings such as the structure of the training industry is not suitable with the labor market, the training program, the training quality has not met the requirements. Practice; Many people who have received vocational training still find it difficult to find a job; many people have to work unsuitable for their profession or profession; the underemployment rate is still quite high ... Theethnic minorityRIN area is mainly mountainous, border, divided terrain, harsh climate, the worst infrastructure in the country, starting from very low; climate change, environmental incidents (Landslide,drought in the provinces of Central Coast ...) occur serious and unpredictable ... Chi production costs, large cargo traffic should be very difficult to attract social resources head socio-economic development, greatly influencing the sustainable development of theethnic minority areaRIN. Therefore, it is necessary to evaluate the effectiveness and impact of vocational training policies and job creation for ethnic minority laborers, thereby proposing suitable models and policies to ensure efficiency and effectiveness. lasting.

Creating jobs for ethnic minorities not only has an economic meaning, but also has a deep social and human meaning. For individual workers, vocational training and employment will improve their education, skills, contribute to perfecting their personality and intellect, thereby helping them to have stable careers, income and improvement. improve life. For society, vocational training and job creation will provide an important workforce, a factor that promotes local economic growth and income, while reducing the negative and social evils. Assembly brought by low literacy.

\section{ACKNOWLEDGMENTS}

The article is the product of a state-level scientific project "Basic and urgent solutions to improve the effectiveness of the policy of conservation and development of ethnic minorities in our country today", CTDT code 42.18/16-20. 


\section{LIST OF REFERENCES}

[1] UBDT, UNDP, IrishAid (2017), Overview of the current economic situation - The society of 53 ethnic minorities is based on the analysis of survey data on socio-economic status of 53 ethnic minorities in 2015, Hanoi.

[2] Tuyen Hoa District People's Committee (2019), Report on the situation of the Chut ethnic group.

[3] People's Committee of Tuong Duong District (2019), O Du Socio-Economic Situation Report 2006 - 2019.

[4] Nghe An Provincial People's Committee (2019), Report on evaluation results, collect information on the socioeconomic situation of $O$ Du ethnic group in Nghe An province; propose supporting items and funding for $O$ Du ethnic socio-economic development in 2019.

[5] People's Committee of Quang Binh Province (2019), Report on situation of socio-economic-social life of the Chut ethnic group in Quang Binh province.

[6] People's Committee of Lam Hoa commune (2019), Report on situation of living of Chut ethnic people.

[7] People's Committee of Nga My Commune (2019), Report on areas related to the socio-economic-social life of ethnic minorities (O Du ethnic group). 